\title{
DESAFIOS DO INVESTIMENTO SOCIAL PRIVADO PARA FORTALECER REDES TERRITORIAIS DE IMPACTO SOCIAL
}

\author{
Fernanda Zanelli e Fábio Dantas Rocha
}

\begin{abstract}
// resumo
O presente artigo trata dos desafios do investimento social privado (ISP) para fortalecer redes territoriais voltadas para o impacto social. A relevância do tema para o campo tem recebido significativo destaque, já que a busca por soluções sociais aos desafios contemporâneos se dá a partir da articulação e da atuação coletiva. Mobilizando bibliografia pertinente e relatos de prática, o artigo apresenta diálogos entre a teoria e a práxis que o conceito de rede pode encadear, aprofunda aspectos ambivalentes que a atuação em rede pode suscitar, elenca desafios comuns para o investidor e destaca recursos possíveis para atuação nessa agenda.
\end{abstract}

| palavras-chave: investimento social privado | redes territoriais | atuação em rede. 


\section{OS ARTIGOS GIFE}

A série Artigos GIFE publica reflexões e análises de pesquisadores brasileiros de diferentes áreas do saber com o objetivo de estimular, ampliar e disseminar a produção de conhecimento qualificado sobre o campo da filantropia, do investimento social privado e da sociedade civil no Brasil.

A partir da premissa de que a produção de conhecimento sobre esses temas tem um papel fundamental na expansão, diversificação e qualificação da ação pública pela sociedade, a iniciativa também pretende contribuir para ampliar as conexões entre o setor, as universidades e os centros de pesquisa, promovendo e apoiando o envolvimento de novos atores com a temática e a circulação ampliada de ideias em torno dela.

Este texto integra a quarta edição dos Artigos GIFE, que propõe a publicação mensal de artigos selecionados por meio de chamada pública e convite a autores especialistas em temáticas específicas e relevantes para o setor, buscando apoiar e fomentar a produção de conhecimento sobre o investimento social no Brasil.

\section{O GIFE}

O Grupo de Institutos Fundações e Empresas (GIFE) é uma organização sem fins lucrativos que reúne associados de origem empresarial, familiar ou independente que investem em projetos de interesse público. Criado em 1989 como grupo de troca e colaboração e institucionalizado em 1995 por 25 organizações, tornou-se referência no campo da filantropia e do investimento social privado no Brasil.

Nesses mais de 20 anos de atuação, tem contribuído para o fortalecimento de práticas e ações a serviço do bem comum no país, trabalhando para expandir, qualificar e fortalecer o investimento social privado, diversificar e ampliar atores e recursos, criar referências e estimular boas práticas de gestão, bem como articulando o setor com a sociedade e a agenda pública. Atualmente, o GIFE reúne mais de 160 associados que, somados, aportam mais de 3 bilhões de reais por ano em projetos próprios e no apoio a projetos de terceiros. 


\section{INTRODUÇÃO}

Da biologia molecular à geometria, a temática de rede tem sido trabalhada por diversos campos do conhecimento. Porém, em nenhum outro tempo histórico esse conceito foi tão capaz de traduzir a essência de uma geração, razão pela qual é frequentemente evocado na sociedade contemporânea. Entre as definições que a palavra carrega, a ideia de relação captura com precisão o sentido e a popularidade do termo. No entanto, um dos significados que o verbete traz é também o de restrição, aspecto pouco mencionado no debate sobre o assunto (BERTONCELLO, VELHO e VERMELHO, 2015). Assim, as ambivalências em relação às redes é o cerne deste artigo, analisando potencialidades, limites e a jornada de investidores sociais que encontram nessa modalidade de ação uma forma de obter maior impacto social.

Duas vertentes foram emblemáticas para o amadurecimento da teoria das redes sociais. Uma, centrada na antropologia social britânica, ocupando-se da interação entre indivíduos em um grupo restrito. E outra, de origem americana, debruçou-se em análises quantitativas, com o objetivo de compreender as dimensões normativas de sistemas culturais (PORTUGAL, 2007). No Brasil, a produção acadêmica em torno das redes teve um crescimento significativo após a virada do milênio - principalmente nas áreas de comunicação e educação - com bastante aderência ao contexto social e político. Manuel Castells e Pierre Lévy são exemplos de autores recorrentes nos estudos que mobilizam categorias analíticas em torno das "questões econômicas e sociais" e das "transformações sociais e culturais" (BERTONCELLO, VELHO e VERMELHO, 2015, p. 879).

É inegável que o avanço das tecnologias e o desenvolvimento de espaços virtuais, dedicados a trocas de informações mais ágeis e espontâneas, foram fundamentais para a difusão, e até para a polissemia, do termo. A partir disso, a palavra redes passou a ser constantemente utilizadas com significados variados nas esferas sociais, políticas e acadêmicas, de maneira que, ao trabalhar nessa temática, se faz necessário circunscrever o objeto que está sendo tratado (ADULIS, 2011).

Nesse sentido, embora seja necessária uma contextualização conceitual, este artigo não aborda a teoria de análise de redes - investigação das interações que emergem da sociabilidade dos sujeitos -, mas navega no campo das iniciativas que colocam a rede como forma de organização (constituída formal ou informalmente), cujo intuito é encaminhar questões sociais, não apenas pela soma de esforços entre os membros, mas pela interface entre eles.

Apesar do recorte de análise se referir prioritariamente a redes de organizações inseridas nos territórios, a bibliografia mostra que nem sempre as fronteiras entre o público e o privado, entre o pessoal e o institucional, são bem definidas nas práticas de rede. Ao investigar a formação do capital social em uma comunidade brasileira, Fontes (2004 apud PORTUGAL, 2007) concluiu que a ação coletiva é atravessada por estruturas de sociabilidade que passam pelo âmbito privado. Ou seja, a determinação do espaço público é afetada pelos laços sociais, levando em conta experiências pessoais dos sujeitos.

O espaço geográfico, por sua vez, é indutor da conexão entre sujeitos e também na sua interação com o mundo, de forma a moldar (e ser moldado) por essa relação. Assim, o território se estabelece também como lócus de atuação social e política de agentes sociais que se "reúnem para discutir conjuntamente propostas de desenvolvimento local e para trocar informações sobre a comunidade e os problemas da região" (ALVEAR, 2008, p. 36, apud LESP, 2019, p. 21). 
Os capítulos a seguir organizam a discussão deste artigo nos seguintes subtemas: 1) tipologias de redes territoriais: elenca diferenças e semelhanças entre iniciativas de rede, bem como eventuais decorrências acerca das características de cada uma; 2) potencialidades e limites: trata de aspectos inerentes às iniciativas de rede que podem representar uma "faca de dois gumes", uma vez que o mesmo fator que suscita vantagens também pode se transformar em armadilhas; 3) obstáculos e atalhos na jornada de quem investe: elucida questões recorrentes no cotidiano dos investidores; e 4) considerações finais acerca do tema tratado.

\section{TIPOLOGIAS DE REDES TERRITORIAIS}

O fato de as redes territoriais encontrarem no espaço geográfico um elemento organizador para sua atuação e identidade enquanto grupo não significa que não existam outras ramificações - temáticas, por exemplo que incidam sobre a formação desses conjuntos. Esta reflexão abre fronteiras para um breve mapeamento das múltiplas tipologias existentes nesse espectro. Algumas variações são explicitadas a seguir, tendo como referências as experiências territoriais.

Uma rede pode ser formada por organizações pertencentes a uma mesma categoria no território, prevalecendo uma característica homogênea entre os membros do grupo. Já outras se destacam pelo desafio de articulação entre diversos setores e instituições da comunidade, tendo, assim, um caráter heterogêneo. A experiência das Redes Locais de Promoção à Leitura, que compõem a Rede Nacional de Bibliotecas Comunitárias, são exemplos de redes entre pares, ainda que cada biblioteca preserve características próprias e estabeleça outras relações nos territórios em que estão inseridas (GUERRA, LEITE e VERÇOSA, 2019). Já as Redes de Territórios Educativos de São Luiz (MA) e Várzea Grande (MT) - iniciativa do Itaú Social, com a coordenação técnica do Centro Integrado de Estudos e Programas e Desenvolvimento Sustentável (CIEDS) - são exemplos de redes municipais que mobilizam uma ampla gama de atores, encaminhando questões que exigem esforços intersetoriais e interinstitucionais (LESP, 2019).

Algumas iniciativas podem estar centradas na regulação de determinado campo, estabelecendo parâmetros, subsídios e normativas para um grupo de instituições semelhantes. Já outras podem estar mais focadas no atendimento direto, tendo como base a colaboração para atingir resultados. Embora o enfoque sejam redes territoriais, para efeito de exemplo, a Associação Brasileira de Organizações Não Governamentais (ABONG) pode ser indicada como rede reguladora (LESP, 2019).

As redes também podem ter diferentes motivações para a sua existência. Entre as diversas possibilidades está a troca de informações e experiências, a incidência política para uma causa ou até mesmo o trabalho conjunto para alcançar um objetivo comum. Tais motivações impactam a forma como cada rede se desenvolve, já que há níveis diferentes de interdependência que, consequentemente, desencadeiam diferentes gradações de complexidade.

O grau de formalização também pode se distinguir para cada iniciativa. Algumas precisam ser estabelecidas por mecanismos formais para a validação de sua atuação: são exemplos, nesse sentido, os consórcios públicos de municípios que se articulam em blocos regionais para viabilizar questões que perpassam os limites geográficos de cada cidade, tais como saneamento básico, sistema de saúde etc. (ITAÚ SOCIAL, 2017). Em outros casos, a informalidade pode ser parte da identidade do movimento, como para os coletivos culturais atuantes nas periferias. Há ainda exemplos de redes de coletivos, como na experiência paulistana Potências Periféricas (AOQUI e SANTOS, 2019).

As circunstâncias de fundação das redes também dizem muito sobre a dinâmica que elas podem assumir. Algumas se constituem de maneira espontânea, em grupos que se formam em torno de um propósito partilhado, ganhando (ou não) robustez gradativamente. Outras vezes, a rede pode ser mobilizada por um agente externo para responder a um desafio específico, podendo ter um horizonte temporal mais bem definido. Situações assim podem trazer vantagens para a estrutura, já que possivelmente haverá mais recursos alocados, mas também pode trazer entraves, já que a motivação não é intrínseca aos participantes. Segundo Lieber e Ferri, "redes formadas como resultado de estímulos externos, especialmente de doadores, são menos sustentáveis no longo prazo do que as que se desenvolvem organicamente, a partir de parcerias preexistentes” (2004 apud ADULIS, 2011, p. 150). 
Em relatos de práticas em torno do fomento a redes, é possível observar o uso de outras nomenclaturas associadas, como as palavras arranjos e alianças. Uma hipótese para o uso desses termos é a possibilidade de acolherem uma maior variação de formatos, já que a palavra rede pode carregar um imaginário de grupo ampliado - com uso de plataformas, governança bem definidas, entre outros elementos -, enquanto alianças e arranjos podem transmitir a ideia de conexões mais livres e até mais simples parcerias entre duas ou três organizações, por exemplo. O Programa Redes e Alianças do Instituto C\&A (atualmente Laudes Foundation) é um exemplo do uso de uma dessas terminologias.

As redes também podem ter arquiteturas diversas, a depender da forma como os fluxos de troca se desenvolvem a partir de laços e nós. Há um arcabouço de estudos a respeito dessas representações visuais. Alguns modelos matemáticos, mais difundidos no campo da ciência da informação, demonstram variações comuns entre redes centralizadas, descentralizadas e distribuídas.

Dialogando com os exemplos relatados na área social, há evidências que também nesse campo a multiplicidade da forma de organização das redes são marcantes. Em algumas iniciativas, determinadas instituições funcionam como hubs para conexão e suporte de outras. É o caso do modelo de impacto coletivo, formulado na Universidade de Stanford. Nessa experiência, há estudos dedicados a reforçar a importância de organizações backbones, cujo papel está centrado na estruturação de uma visão estratégica, no suporte para realização de atividades, na mediação de práticas, no fortalecimento do propósito comum e aspectos normativos, além de na mobilização de recursos (KANIA e KRAMER, 2011).

Outras iniciativas convocam representantes para compor um núcleo, no intuito de organizar fluxos de tomada de decisão e atuar na mobilização de outros membros. Por exemplo, as redes de São Luiz e Várzea Grande (Redes de Territórios Educativos) contam com grupos gestores em suas dinâmicas de governança (LESP, 2019).

Há também outras configurações ainda mais complexas, de diferentes níveis, como na experiência do Fundo Iniciativa Comum, da Rede América (2010), em que um grupo de investidores destinaram recursos a três organizações referências, que, por sua vez, mobilizaram redes locais a partir de um edital de fomento à projetos (MARTINHO, 2010).

O Quadro 1 traz uma síntese das tipologias trabalhadas neste capítulo.

\section{Quadro 1 - Características e variações de redes}

\begin{tabular}{ll} 
Característica & Variações (1) \\
\hline Composição & Homogênea, heterogênea \\
\hline Natureza & Regulação - atuação direta \\
\hdashline Objetivos & Troca de experiências/ informações; incidência política; atuação conjunta, etc. \\
\hline Grau de formalização & Formais, informais \\
\hline Circunstância de fundação & Espontânea, mobilizada por agentes externos \\
\hline Nomenclaturas associadas & Arranjos, alianças, parcerias, etc. \\
\hline Arquiteturas diversas & Centralizadas, descentralizadas, distribuídas etc.
\end{tabular}

Fonte: elaboração própria.

Nota: (1) esta coluna não tem a pretensão de esgotar as possibilidades a partir de cada característica, mas de trazer exemplos comuns de variações.

Além disso, analisando iniciativas no campo social, há uma recorrência de características híbridas nas redes, já que entre um oposto e outro (por exemplo, formal/informal) podem existir múltiplas gradações. 


\section{POTENCIALIDADES E LIMITES}

É muito comum, ao falar de redes, que apenas elementos positivos sejam ressaltados. Pouco se discute sobre os limites que elas podem ter a partir dos mesmos aspectos que configuram certas vantagens. Esta seção é dedicada a refletir sobre questões caras a práticas de redes e seus possíveis contrapontos, tais como: 1) o ganho de escala e a necessidade de fortalecimento das iniciativas individualmente; 2) a ampliação da interface com um maior número de atores e a possível limitação do perfil alcançado; 3) colaboração e disputa, 4) e, por fim, horizontalidade e assimetrias de poder.

Como já se sabe, são muitos os desafios inerentes ao quadro crítico de desigualdade social que o país enfrenta historicamente, ao passo que os recursos dedicados a programas e políticas são escassos. Ainda que as instituições sociais privadas não tenham o papel de universalizar seus esforços - já que essa é a responsabilidade da política pública -, para a maioria há uma busca constante no equilíbrio entre a qualidade do trabalho desenvolvido e a possibilidade de ampliação do alcance. De acordo com o Censo GIFE 2019, referente a 2018, a maior parte dos investidores (60\%) afirma considerar o ganho de escala de seus programas e projetos. Esse quadro faz com que a atuação em rede seja vista como uma aliada para um "efeito multiplicador" (ADULIS, 2011, p. 136)

Ainda que as redes possam oferecer capilaridade, é preciso considerar que os resultados dos esforços coletivos não substituem a atuação por unidade, pois são diferentes níveis de ação. Assim, destaca-se um primeiro limite. Nos esforços em rede, são raras as oportunidades para que a unidade pertencente ao grupo obtenha subsídio financeiro e técnico para se fortalecer enquanto instituição. Para Adulis (2011), uma das principais razões para o fracasso das redes é o fato de cada organização participante colocar seus propósitos como prioritários, deixando de lado as questões relacionadas à atuação conjunta. Em complemento ao que traz o autor, deve-se considerar a histórica precarização das condições de trabalho em organismos sociais, que torna ainda mais desafiador o engajamento em compromissos externos. As OSC, instituições-chave nas redes territoriais, são exemplos das fragilidades institucionais presentes entre as iniciativas sociais. Segundo o Instituto de Pesquisa Econômica Aplicada (IPEA, 2018, p. 21): " $83 \%$ das OSC não apresentam vínculos formais de emprego; outras 7\% delas têm até dois vínculos de trabalho, totalizando $90 \%$ de OSC que possuem até dois vínculos”. Esses dados sublinham o fato de que, a maior parte das OSC são de porte micro, com um grande contingente de vínculos informais e de mão de obra voluntária. Diante desse cenário, são necessárias iniciativas complementares que garantam a saúde desses organismos em suas esferas individuais, pois, ao negligenciar a vitalidade de cada ponto de uma rede, o resultado é o esgarçamento do tecido coletivo.

Embora seja comum concluir que as iniciativas em rede podem ser vantajosas para ampliar a mobilização e o contato com um maior número de atores, nem sempre isso quer dizer o alcance de grupos sociais historicamente marginalizados. Para Portes (1998 apud PORTUGAL, 2007), uma das características negativas do capital social - noção que se aproxima da teoria das redes sociais - é "a exclusão dos que estão fora do grupo. Os mesmos laços que trazem benefícios para os membros da rede, muitas vezes, impedem o acesso a outros" (PORTUGAL, 2007, p. 22).

Com essa ideia, outra ambiguidade que as redes podem manifestar é exposta. Se, por um lado, pode haver o fortalecimento de um conjunto constituído, por outro é possível ocorrer o distanciamento sistemático de iniciativas que não conseguem chegar nas redes. Muitas organizações debilitadas institucionalmente, sobretudo aquelas que se encontram fora do eixo Sudeste e das grandes capitais, não têm condições estruturais para se manterem articuladas. Assim, se há intenção de que o trabalho em rede potencialize a interface com diferentes organizações/ movimentos, são necessárias estratégias para que haja esse alcance. Não considerar esses fatores pode significar, a longo prazo, a restrição do diálogo a apenas um perfil selecionado, sem a ampliação de interações, como a agenda preconiza.

As condições sociais e políticas que atravessam o espaço (e seu uso), para além do território físico, são elementares em se tratando de redes territoriais. Para Milton Santos: 
[...] o espaço se dá ao conjunto dos homens que nele se exercem como um conjunto de virtualidades de valor desigual, cujo uso tem de ser disputado a cada instante, em função da força de cada qual (SANTOS, 2006, p. 215).

Embora a colaboração seja tratada como um pressuposto em muitas redes, as disputas também estão grafadas nas relações de sociabilidade e interação no espaço. No entanto, no âmbito político, as disputas e os conflitos (quando na esfera da lei e da ética) fazem parte da dinâmica democrática e contribuem para o amadurecimento do debate. Ainda que iniciativas em rede estejam sendo implementadas para superação da tradicional competição por recursos no campo, por exemplo, ela não pode ser vista como solução definitiva e automática para a questão.

Seja no espaço virtual ou físico, as redes são resultantes de dinâmicas sociais, e, como tais, carregam as assimetrias de poder existentes na sociedade. O estudo "Redes e capacidade de ação na sociedade civil", a partir da teoria de análise de redes, observou assimetrias de poder e a capacidade de influência nas relações de 202 organizações sociais. Embora as conclusões permitam múltiplos olhares e não foquem nas iniciativas organizadas em rede, um dos resultados demonstra o caráter desigual na dinâmica de interação entre as OSC pesquisadas. Segundo o relatório, alguns "atores, por motivos diferentes, se desempenham como referência para entidades menos centrais ou francamente periféricas” (BICHIR, CASTELLO e LAVALLE, 2007, p. 31).

\section{A JORNADA DE QUEM INVESTE: OBSTÁCULOS E ATALHOS}

Para Portugal (2007), a dimensão interdisciplinar das redes as coloca como mecanismos para o enfrentamento de questões de alta complexidade. A busca por soluções aderentes às demandas atuais explica o interesse massivo por iniciativas que conectem diferentes instituições, setores e expertise em prol da transformação social. No último Censo GIFE, 47\% dos respondentes afirmaram participar de redes, mobilizados pela crença na atuação conjunta como forma de alcançar objetivos comuns.

No que se refere às iniciativas de base comunitária, há demandas de esforços urgentes de análise e fomento, já que mobilizam agentes na luta por garantia de direitos humanos, na maior parte das vezes sem as condições institucionais adequadas para fazer frente a esse desafio. O olhar para as redes territoriais se justifica ainda mais ao constatar a ausência desses agentes locais em redes estratégicas de abrangência regional ou nacional. Além disso, também são raras as oportunidades de intercâmbios entre pares para esse público. Manter-se em rede demanda recursos, invariavelmente insuficientes nas instituições públicas e privadas inseridas nas comunidades.

Cerca de um terço dos respondentes do Censo GIFE 2019 afirmou investir no fortalecimento institucional/ gestão de redes ou grupos. Ao mesmo tempo, houve aumento no aporte financeiro em prol do desenvolvimento comunitário, de 54\% em 2018 contra 31\% em 2016 (COMUNITAS, 2019). Esses dados podem indicar uma tendência de crescimento no fomento a iniciativas comunitárias, a partir do reconhecimento da legitimidade e da potência desse tipo de experiência. Ainda assim, o investimento nessa agenda requer avanço imediato para que consiga refletir as urgências que emanam de um contexto social e político cada vez mais desgastado.

A maior parte dos investidores (94\%) diz integrar algum tipo de rede, sendo que mais da metade (52\%) o fazem pela valorização da troca de conhecimentos e informações. Curioso, no entanto, é que apenas $6 \%$ desse grupo encontra nesse tipo de atuação oportunidades de conexão com organizações de diferentes perfis (GIFE, 2019). Essa polarização representa uma antítese do setor. De um lado, há um discurso sobre o conhecimento compartilhado, mas, de outro, são poucas as ações para que esse conhecimento seja composto por diferentes olhares e lugares de fala (RIBEIRO, 2017).

O perigo da história única é que ela se constrói na ausência de pontos de vistas e de saberes de grupos marginalizados socialmente. Assim, preserva apenas discursos construídos nas esferas de conhecimento 
legitimadas como detentoras do saber universal. Esferas essas que, caracterizadas pelos privilégios de uma maioria branca, masculina e hetero-normativa, concentram não só o capital financeiro, mas, também, o capital simbólico (ADICHIE, 2019). Na esteira desse quadro social crítico, não só há urgência de fomento a redes organizadas a partir dos territórios, como também de integração dessas organizações em outras redes já consolidadas no setor.

Há ainda a necessidade de reflexão constante sobre o papel dos investidores. A proximidade de quem investe com as redes apoiadas, seja como membro ou somente como mantenedor, suscita dilemas que exigem cautela e cuidado cotidiano. Como mantenedor, é preciso examinar os objetivos que respaldam a decisão do apoio, garantindo que o interesse maior seja pelo fortalecimento das soluções sociais desenvolvidas pelos atores legitimados nos territórios, a partir de questões que o próprio grupo considere prioritárias. Já como membro, é fundamental a ponderação de que - ainda que haja um pacto (explícito ou implícito) pela suspensão temporária das desigualdades entre os atores envolvidos, na tentativa de reproduzir certa horizontalidade - isso não basta para que ocorra o reconhecimento dos interesses e necessidades de todos de maneira equânime. As disparidades sociais enraizadas no contexto político, econômico e cultural impedem que as redes sejam ambientes capazes de neutralizar a condição desigual (FRASER, 1990). Portanto, a "desneutralização" das redes, ou seja, sua análise como mecanismos de interação social que consideram as assimetrias na distribuição de poderes materiais e simbólicos, é o primeiro passo na direção de cultivar diálogos mais abertos e coerentes com os diversos grupos sociais. É importante lembrar que são essas assimetrias de reconhecimento e legitimação, e sua naturalização, que potencializam os contrastes sociais que esforços coletivos buscam solucionar.

O descompasso em relação à duração dos apoios também dificulta o investimento. Para muitos doadores, a disponibilidade de recursos depende de um orçamento anual, inviabilizando compromissos financeiros que ultrapassem o ano fiscal. Na contramão, estudos comprovam que a maturidade das redes depende de financiamento a longo prazo. Além disso, a frequente equiparação de redes a projetos faz com que, muitas vezes, elas precisem responder às mesmas regras de apoios direcionados a OSC ou programas, mesmo se tratando de experiência incompatíveis (ADULIS, 2011, p. 153). A destinação de recursos a rubricas específicas é outra prática que não contribui para o apoio a redes autônomas, pois muitas vezes é necessária a eleição de pautas plurais e inconstantes. No recorte de empresas, chega a $82 \%$ o percentual que afirma apoiar iniciativas de terceiros a partir de linhas programáticas já estabelecidas (GIFE, 2018).

Ao observar os principais problemas reportados pelas redes, não surpreende que quase a totalidade esteja relacionada a questões de governança e sustentabilidade. Isso evidencia a importância do fortalecimento da gestão, porém, pode revelar também um excesso normativo, capaz de desbotar o motivo final pelo qual a rede existe. Para Adulis (2011, p. 137): "uma forma de evitar cair nesta armadilha é explorar melhor as funções que a rede poderia desempenhar".

Por fim, os processos de monitoramento e avaliação também representam grandes entraves. A imprevisibilidade e a pluralidade de expectativas (muitas vezes pouco aderentes à realidade) são alguns obstáculos (WILSON-GRAU, 2011). Especialistas alertam ainda sobre necessidade de revisão de metodologias e instrumentos adequados já que, conforme define Patton, as redes são "agentes de mudança social não lineares e dinâmicos” (WILSON-GRAU, 2011, p. 164).

Ainda que haja muitos obstáculos - como de costume, nos caminhos a serem desbravados -, é possível, graças à profusão de pesquisas e experiências voltadas a iniciativas de rede, mapear atalhos para facilitar a jornada daqueles que, corajosamente, elegem essa via para promoção de transformações sociais perenes.

A comunicação é um recurso valioso para a atuação em rede. Aproxima-se dessa vertente do conhecimento contribuições metodológicas promissoras para a ação coletiva, vindas de teorias da mobilização social. Segundo Toro e Werneck (2007, a mobilização social requer: 1) um imaginário coletivo (objetivo comum); 2) produtores sociais (de onde partem mensagens-chave); e 3) reeditores (que adaptam e transmitem a mensagem). Já para Ganz (2010), a estratégia de mobilização, resumidamente, passa por: 1) construção de narrativas de engajamento; 2) desenvolvimento de lideranças; e 3) fortalecimento 
da capacidade de ação e de organização. Elementos como esses oferecem pistas de como organizar e sustentar a colaboração para um objetivo partilhado.

Devido à complexidade que essa agenda carrega, uma forma de iniciar o investimento na temática é criar ambiências favoráveis a trocas entre atores e organizações do território. Viabilizar o intercâmbio de experiências, valorizando a relação formativa entre pares, não é trivial em situações onde educadores e gestores sociais trabalham isolados e, cada vez mais, extenuados pela densidade das questões com que lidam.

Antes mesmo de aprofundar o trabalho em redes dedicadas à produção conjunta, incentivar e facilitar a existência de comunidades de práticas - dedicadas ao compartilhamento de experiências e gestão do conhecimento colaborativa, com vistas à inovação - pode ser um passo promissor no reconhecimento dos saberes inerentes ao grupo, além de um importante alicerce para o avanço em iniciativas de maior grau de dificuldade.

O reconhecimento do legado das redes enquanto processo de ação coletiva, e dos saberes acumulados nessas experiências, com o objetivo de compor narrativas plurais de conhecimento para o campo social, informando outras práticas do ISP, é outra linha importante de atuação para investidores que enxergam a prioridade dessa agenda.

\section{CONSIDERAÇÕES FINAIS}

O fomento a iniciativas de redes territoriais é atravessado por potencialidades, mas também por algumas armadilhas. O próprio termo traz consigo uma gama de sentidos, que terminam por causar confusões a respeito dos significados e objetivos dessas experiências. Foram ressaltadas variações possíveis no desenho de iniciativas de rede, bem como aspectos controversos, tais como: escala versus qualidade, coletivo versus individual, ampliação versus restrição, colaboração versus disputas, horizontalidade versus assimetrias de poder.

Foram elencados desafios para o investimento em iniciativas comunitárias, tais como o papel do doador, a incompatibilidade na duração do apoio e questões de monitoramento e avaliação. Mas também foram destacados recursos, como as contribuições da mobilização social e a valorização de instâncias de troca, do processo e do legado.

Identificar as lacunas do campo e agir para endereçá-las é um passo importante na consolidação de redes mais fortes e eficazes em favor de objetivos compartilhados, tendo como valor primeiro a busca pela equidade e o reconhecimento de uma narrativa social que considere as diversas vozes que a compõem.

Por fim, é preciso salientar - sobretudo em tempos de incertezas - que há de se ter sensibilidade para acolher questões que surgem pelo caminho, pois não há outro meio possível. Em entrevista para o El País, Bauman (2016) ressaltou que "a diferença entre a comunidade e a rede é que você pertence à comunidade, mas a rede pertence a você". Apesar de o sociólogo se referir às redes sociais digitais nesse trecho, é inevitável o impacto que a afirmação provoca à luz da reflexão sobre iniciativas de rede em geral. Diferentemente das comunidades, que são imprevisíveis e dizem sobre um conjunto, as redes tendem a curadorias que passam por escolhas unitárias. Assim, é necessário equilibrar o fio de navalha entre intencionalidade e artificialidade, entre organização e controle. $\mathrm{O}$ acolhimento do que é emergente do campo é chave para despertar o sentido de fazer parte, conexões verdadeiras que a longo prazo irão delinear experiências sólidas e reais. No limite, esse deveria ser o objetivo final de todas as iniciativas de rede. 


\section{REFERÊNCIAS}

ADICHIE, Chimamanda Ngozi. O perigo de uma história única. $1^{\text {a }}$ edição. São Paulo: Companhia das Letras, 2019.

ADULIS, Dalberto. A profusão das redes: gestão e fomento na promoção do desenvolvimento. In: MARTINHO, Cassio; FELIX, Cristiane (org.). Vida em rede: conexões, relacionamentos e caminhos para uma nova sociedade. Barueri: Instituto C\&A, 2011, p. 129-159. Disponível em: <https://sinapse.gife.org.br/download/vida-em-redeconexoes-relacionamentos-e-caminhos-para-uma-nova-sociedade>. Acesso em: 20 jun. 2020.

AOQUI, Cássio; SANTOS, Diana. Novas narrativas para o investimento social e acesso a recursos nas periferias. Artigos Gife, v. 1, n. 2, artigo 4, 2019. Disponível em: <https://sinapse.gife.org.br/download/ novas-narrativas-para-o-investimento-social-e-acesso-a-recursos-nas-periferias〉. Acesso em: 20 de jun. 2020.

BAUMAN, Zygmunt. Zygmunt Bauman: as redes sociais são uma armadilha. Entrevista concedida a Ricardo de Querol, El País, Cultura, set. 2016.

BERTONCELLO, Valdecir; VELHO, Ana Paula; VERMELHO, Sônia. Sobre o conceito de redes sociais e seus pesquisadores. Educação e Pesquisa, v. 41, n. 4, p. 863-881, out/dez. 2015. Disponível em: <https://doi.org/10.1590/s1517-97022015041612>. Acesso em: 20 jun. 2020.

BICHIR, Renata; CASTELLO, Graziela; LAVALLE, Adrian. Redes e capacidade de ação na sociedade civil: o caso de São Paulo/ Brasil. Revista Hispana para el Análisis de Redes Sociales, n. 12, jun. 2007.

COMUNITAS. Benchmarking do investimento social corporativo, 2019. Disponível em: <https://bisc. org.br/bisc-2019/as-mudancas-na-conducao-das-parcerias/>. Acesso em: 2 mar. 2020.

FRASER, Nancy. Rethinking the public sphere: a contribution to the critique of actually existing democracy. Duke University Press, 1990. Disponível em: http://www.jstor.org/stable/466240 . Acesso em: 29 de jan. de 2020.

GANZ, Marshall. Leading change: leadership, organization, and social movements. Boston: Harvard Business Press, 2010.

GIFE - Grupo de Institutos, Fundações e Empresas. Censo Gife 2018. 2019. Disponível em: https:// gife.org.br/censo-gife/. Acesso em: 20 fev. 2020.

GUERRA, Adriano; LEITE Camila; VERÇOSA Érica. Percursos formativos: saberes das bibliotecas comunitárias. v. 2. São Paulo: Rede Nacional de Bibliotecas Comunitárias, 2019.

IPEA - Instituto de Pesquisa Econômica Aplicada. Perfil das organizações da sociedade civil no Brasil. Brasília: Ipea, 2018.

ITAÚ SOCIAL. Diálogos sobre gestão municipal: câmaras técnicas de consórcios. São Paulo: Itaú Social, 2017. Disponível em: <https://fundacao-itau-social-institucional-producao.s3.sa-east-1.amazonaws.com/downloads/ publicacao-melhoria_1513268644.pdf>. Acesso em: 20 jun. 2020.

KANIA, John; KRAMER, Mark. Collective impact. Stanford Social Innovation Review, 2011. Disponível em: 〈https://ssir.org/articles/entry/collective_impact>. Acesso em: 20 jun. 2020.

LESP - Laboratório de Estudos do Setor Público. Pesquisa sobre atuação em rede de organizações da sociedade civil: relatório final. São Paulo: Itaú Social, 2019. Disponível em: <https://www.itausocial.org.br/ wp-content/uploads/2018/06/Redes_relat\%C3\%B3rio-completo.pdf>. Acesso em: 20 jun. 2020. 
MARTINHO, Cássio. Iniciativa comum: trajetórias e aprendizados com as redes e coletivos de jovens. São Paulo: Rede América, 2010. Disponível em: <https://sinapse.gife.org.br/download/iniciativacomum-trajetoria-e-aprendizado-com-as-redes-e-coletivos-de-jovens>. Acesso em: 20 jun. 2020.

PORTUGAL, Silvia. Contributos para uma discussão do conceito de rede na teoria sociológica. Oficina do CES n. 271; mar. 2007. Disponível em: <https://eg.uc.pt/bitstream/10316/11097/1/Contributos\%20 para $\% 20$ uma $\% 20$ discussão $\% 20$ do $\% 20$ conceito $\% 20$ de $\% 20$ rede $\% 20$ na $\% 20$ teoria $\% 20$ sociológica.pdf $>$. Acesso em: 20 jul. 2020.

RIBEIRO, Djamila. O que é lugar de fala? São Paulo: Letramento, 2017.

SANTOS, Milton. A natureza do espaço: técnica e tempo, razão e emoção. 3. ed. São Paulo: Hucitec, 1999.

TORO, José Bernardo; WERNECK, Nísia. Mobilização social: um modo de construir a democracia e a participação. Comunicação Social 2. Belo Horizonte: Autêntica, 2007.

WILSON-GRAU, Ricardo. O desafio da complexidade na avaliação das redes. In: MARTINHO, Cassio; FELIX, Cristiane (org). Vida em rede: conexões, relacionamentos e caminhos para uma nova sociedade, Barueri: Instituto C\&A, 2011. Disponível em: <https://sinapse.gife.org.br/download/vida-em-redeconexoes-relacionamentos-e-caminhos-para-uma-nova-sociedade>. Acesso em: 20 jun. 2020. 
OS AUTORES

\section{Fernanda Zanelli \\ fefrazanelli@gmail.com}

Mestranda em Ciência da Informação pela Escola de Comunicação e Artes da Universidade de São Paulo (ECA-USP). Graduada em Comunicação Social e Pós-graduada em Globalização e Cultura (Fundação Escola de Sociologia e Política) e Gestão de Políticas Culturais (Universitat de Girona). Iniciou sua carreira no campo social em 2001, no atendimento a populações indígenas de todo o Brasil. Desde 2007 atua no investimento social privado, sendo especialista na área de comunicação do Itaú Social. Tem experiência de pesquisa e sistematização em trajetórias juvenis, juventudes e religião, redes territoriais, fomento às iniciativas da sociedade civil, memória e direito à cidade.

\section{Fábio Dantas Rocha \\ fabiodanrocha@gmail.com}

Doutorando em História Social pela Universidade de São Paulo (USP). Tem graduação e mestrado em História pela Universidade Federal de São Paulo (UNIFESP). Há sete anos atua na educação básica, no ensino superior e na formação de educadores e gestores no desenvolvimento de práticas e metodologias ativas para o ensino de jovens e adultos. Consultor no campo de organizações da sociedade civil, escolas e investimento social privado. Autor do "Guia itinerários da experiência negra - um passeio histórico por São Paulo” (2017) e membro do coletivo Crônicas Urbanas. 
Supervisão: José Marcelo Zacchi e Gustavo Bernardino

Coordenação: Carolina Magosso

Produção editorial: Gleice Regina Guerra

Apoio: Graziela Santiago

Comitê de seleção: Ana Lúcia D'Império Lima, Fábio Silva

Tsunoda, Laura Leal e Lívia Menezes Pagotto

Diagramação: Alastra, Comunica.

Impressão: Forma Certa

ISSN: 2674-8061

DOI: doi.org/10.33816/gife.20200202a5

(c) 2020 GIFE - Grupo de Institutos Fundações e Empresas

\title{
(C) (i) ()
}

Este material é disponibilizado sob a licenca Creative Commons Atribuição Não Comercial 4.0 Internacional. http://creativecommons.org/licenses/by-nc/4.0

As opiniões e análises expressas nesta publicação não necessariamente refletem as do GIFE.

\author{
Apoio institucional \\ Alana \\ Ford Foundation \\ Fundação Bradesco \\ Fundação Lemann \\ Fundação Tide Setubal \\ Instituto Unibanco \\ Laudes Foundation
}

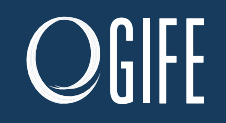

